\title{
Design of Credit Rating Service System in Electricity Market
}

\author{
Bai Shunming ${ }^{1, a}$, Yang Jianhua ${ }^{1, b}$, Liu Dunnan ${ }^{2,3, \mathrm{c}}$, and He Qian ${ }^{2, \mathrm{~d}}$ \\ ${ }^{1}$ Central China Branch of State Grid Corporation, Wuhan 430077, China \\ ${ }^{2}$ North China Electric Power University, Changping District, Beijing 102206, China \\ ${ }^{3}$ State Key Laboratory of Alternate Electrical Power System With Renewable Energy Sources(North \\ China Electric Power University), Changping District, Beijing 102206, China \\ ayjh1010@tom.com, b227262318@qq.com, ${ }^{\mathrm{c}} 1270029512 @ q q . c o m,{ }^{d}$ heqian031506@163.com
}

Keywords: electricity market, credit rating, graded service

Abstract. The advancement of electricity market reform and the outline of "Social Credit System Construction Plan" of the State Council all require the power industry to pay close attention to the construction of the electricity market credit system. In addition to the credit rating and credit regulation of power market members and other passive means, a credit rating service system based on the market members should be designed, so that market members can actively improve their credit and reduce the behavior of dishonesty. This paper designs the respective rating service system for power generation enterprises, sales enterprises and users.

\section{Introduction}

Electricity market credit construction is an important factor to maintain market stability and coordinated development. However, both the construction of credit evaluation system or strict market supervision system are passive means and methods to maintain the market credit, whose effectiveness are related to government control efforts, and can not effectively guide the market members to join the power market credit construction. Therefore, to guide the power market members to actively participate in the power market credit construction, reduce their own dishonesty, enhance the credit rating, and create a good credit environment, we must design an effective market mechanism, make credit as an important factor in market competition. Based on the results of the credit evaluation of the main body of the electricity market, design a differentiated service system to enable better market members with higher credit ratings to get better, faster and better service, at the same time, set more strict rules for poorly credited members. It not only protects the market fair, but also reduces the possibility of credit risk occurred.

The design of credit rating service system of electricity market should include differentiated market access and exit mechanism, differentiated market services and other aspects. Generally speaking, the principle should be: the higher the credit rating of market members is, the more type and scope markets can be participated in, the looser the provision of some market rules is, the higher the priority of contract transactions is. The design of credit rating service system of electricity market is shown in Fig. 1. 


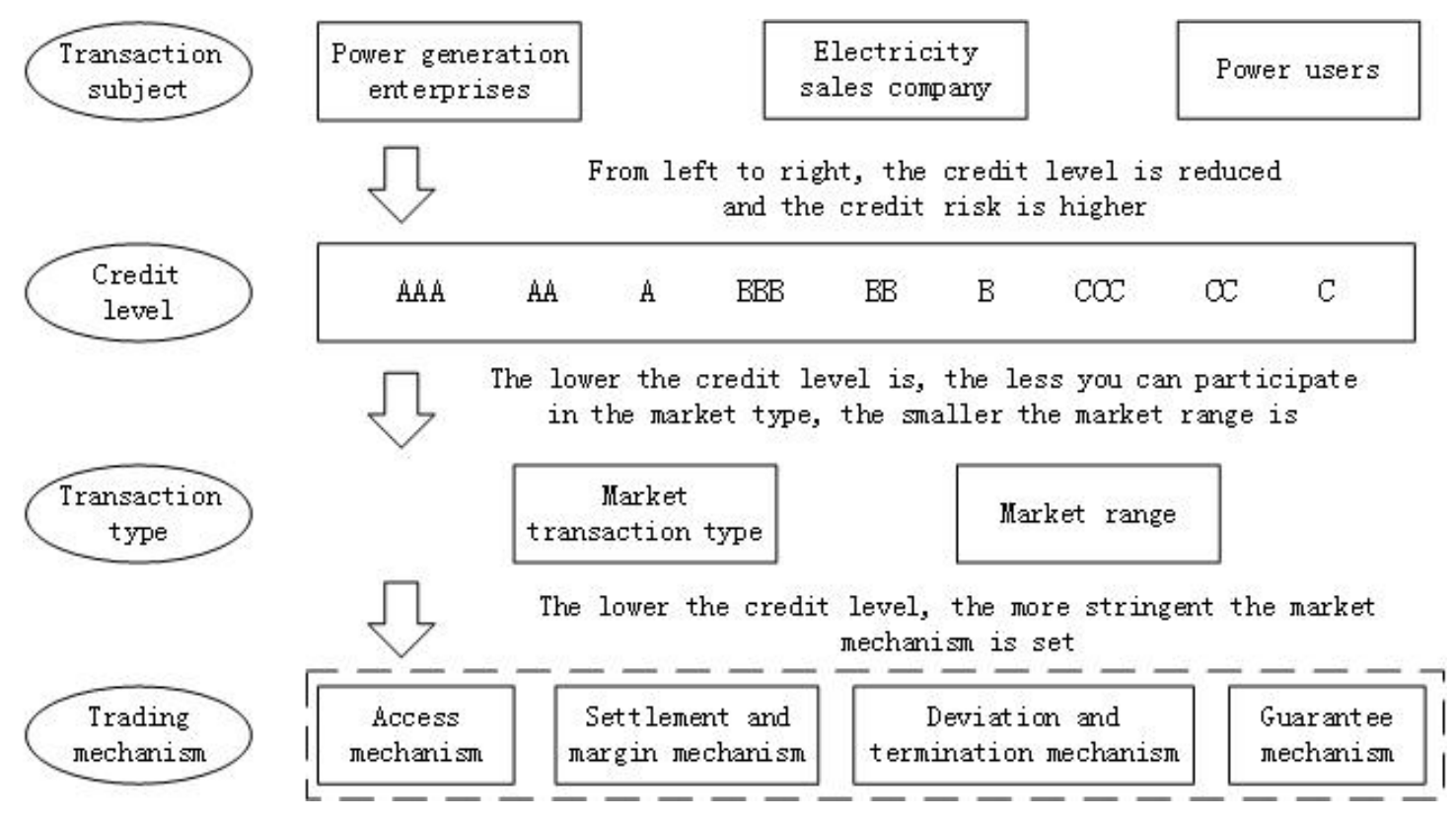

Fig. 1. The design of credit rating service system in electricity market

\section{Design of credit rating service system for power generation enterprises}

Market access mechanism based on credit evaluation of power generation enterprises. The approval authority of market access is an administrative resource with scarce characteristics. It should be based on the fair and open security of the power grid, include the results of credit examination into the market access indicators, and establish the market access and elimination mechanism, so that the credit bottom line and the average level of market members have always been maintained above an acceptable limit. Good credit market members can be given priority in new trading breeds; for poor credit market members, we can consider depriving the right to enter the corresponding sub-market without affecting the safe and stable operation of the system. The specific design is as follows:

- The market participants in the sub-market competition are determined by the power regulatory agencies. The unit that is the subject of market competition must enter the sub-market and participate in the market competition according to the rules. If it is accepted as a market competition subject and does not enter the sub-market or withdraw from the sub-market, we can deprive him of the right to enter all other sub-markets at the same time and determine the annual utilization hours by non-competition unit. The annual utilization hours of non-competition units shall in principle be less than the average utilization hours of competing units. Specific regulations shall be determined according to the rules of each sub-market.

- For the better credit market members, in addition to allowing them to conduct transactions in the primary market, but also further open the secondary market, providing market members with more adequate opportunity to further explore the trading space and voluntarily achieve win-win transaction results; for the poor credit market members, do not give it the right to enter the secondary market transactions.

- For the better credit market members, in the development of new varieties of transactions, we can consider giving priority to enter if they are in line with the basic standards of compliance.

- To the transaction of market members whose credit level is above a certain level, we can provide them with arbitrage opportunities in different sub-market. In bilateral transactions, open a larger span of transaction, providing different sub-market arbitrage opportunities.

- For the poor credit members in a sub-market competition, deprive them of access to all sub-market after confirmation, and determine the number of utilization hours according to non-competitive units. 
Security check and congestion management mechanism based on credit evaluation of power generation enterprises. The presence of transmission congestion will have an important impact on market operations and transactions. On the one hand, the frequent occurrence of transmission obstruction affect the safe and stable operation of the power system and continuous reliable power supply, we should ensure the reasonable investment in transmission to ensure the backbone line and the key channel unimpeded; on the other hand, we must be fully aware that reasonable power grid investment under certain transmission obstruction is inevitable, and a line where transmission congestion may occur is possibly a scarce resource, with great market value and market function. If it is fully utilized, preferentially assigned to the power generation enterprises which create greater social benefits, it will form an effective positive incentive. The establishment of credit system of power generation enterprises will provide effective criteria for this. Considering the credit status of power generation enterprises, it is possible to give priority to the transmission enterprises with good credit records and create greater social benefits to ensure their completion of the trading plan.

This priority allocation is mainly reflected in the security check. When the transmission line is blocked, and need implement reduction for the transaction, we can implement transmission congestion management approach based on credit assessment at this time: blocking management in competition transaction is still the same as current mechanism, makes unconstrained power as the base, according to the spread from small to large to cut; in the same spread, look at the credit situation, the units with low offer and high bid rate are given priority to complete, the transactions with low deal price are given priority to complete, and the units with market forces are given priority to implement the congestion management. This congestion management approach will effectively motivate the units to offer a reasonable price, maintain their own credit status, and reduce possible benefits of market members who use market power, thereby inhibiting the use of market forces in the market.

Priority contracting mechanism based on credit evaluation of power generation enterprises. From the physical characteristics point of view, there is a more obvious supply lag in the power industry, that is, the construction and production of generating units take a long time to achieve, this feature is likely to cause greater fluctuations in power supply and demand. When the supply is in short, the power generation enterprises will have a greater impulse to lift the price, resulting in a sharp rise in market electricity prices, the market order will be a great challenge; after a period time of construction boom, the relation between supply and demand will be completely reversed, many units will have to face the difficult situation where they have no electricity to generate, the normal operation of market will be also affected. At this time, we can resolve it by designing and adopting priority contract mechanism based on credit assessment, the specific design is as follows:

When the market will maintain oversupply for some time in the future, on the basis of fully respecting the laws of market, complying with market rules and voluntary two sides of transaction, look at the credit records of power generation enterprises in the past period. In the case of same offer, for power generation companies with good historical credit and low average offer, organize power grid companies and power users to give priority to their power contracts, so that these power generation enterprises can be relatively smoothly through the downturn of the year.

This mechanism provides better-credit power generation enterprises with expectation to solve production difficulties in the case of market oversupply, thus to a certain extent, motivating them to curb the initiative to earn their own excess profits in market short supply.

Priority power construction project approval mechanism based on the credit evaluation of power generation enterprise. The application and approval of electric power construction are important matters involving the development of power generation enterprises, and important factors affecting power generation enterprises to form market force in the electricity market. Therefore, it is necessary to put the results of power generation enterprise credit assessment into the enterprise qualification review in power construction project approval process.

To the power generation enterprises whose credit rating is below a certain level in power market, in the cancellation of its qualifications to enter into market, we should further limit its new power 
construction projects; in the application of new power construction projects, we should adhere to the same conditions to preferentially approve better-credit power generation enterprises.

\section{Design of credit rating service system for electricity sales enterprises}

Electricity sales enterprises are the marketed product after new electricity reform, with the continuous improvement of the electricity market reform, the number of electricity sales companies in the market increased linearly, and the strength of electricity sales companies were uneven, and because of the lack of corresponding market supervision mechanism, the credit risk is extremely high. Therefore, we should design credit rating service system for electricity sales enterprises, and gradually eliminate the lower strength, lower credit business.

Market access and exit mechanism based on credit evaluation of electricity sales enterprises. The market access mechanism of the electricity sales enterprises is similar to that of the power generation enterprises. For good credit market members, they can be given priority to enter in the new transaction varieties; for poor credit market members, we can consider depriving their right to enter the corresponding sub-market without affecting the safe and stable operation of the system.

In the "2017 Yunnan Electric Power Market Sales Company Credit Evaluation Mechanism (Trial)", Yunnan Province has made relevant provisions to refer to.

Credit rating of $\mathrm{D}$ will be forced to withdraw from the market, directly into the blacklist of electricity sales enterprises. Take measures about the blacklist of the electricity sales companies and parties, within three years no longer accept the enterprise registration application, no longer accept the blacklist enterprise legal representative as other sales company legal person, directors and other registration applications, and the provincial relevant government departments follow the program to implement joint undertaking mechanism. After the rectification of blacklist of electricity sales enterprises, fulfilling the access procedure and entering into electricity market, the initial credit system evaluation level is automatically adjusted to B level.

Margin mechanism based on credit evaluation of electricity sales enterprises. At present, there are a number of provinces formulating that electricity sale companies should pay the margin in market transactions. For example, "Access and Exit Implementation Details of Electricity Sale Companies in Hunan Province (Draft)", has a special description about margin system: electricity sale companies must pay electricity sale margin for third-party financial institutions (to be determined )in accordance with 5-10\% of total assets, implementing year-on-year linkage system between the amount of margin and the scale of sales.

By paying the deposit, we can limit the electricity sale companies' default, but also occupy the cash flow of electricity sale companies' business. So we can set different amounts of margin according to the credit rating of sales company, the higher the credit rating is, the less margin is required to pay, the lower the credit rating is, the more margin is required to pay. This will not only reduce the default risk of credit-poor companies, but also establish a competitive advantage for high credit enterprises, and guide the healthy development of market.

Yunnan Province has taken the lead in the establishment of such a mechanism, this paper refers to the relevant provisions of "2017 Yunnan Electric Power Market Sales Company Credit Evaluation Mechanism (Trial)", and sets sales company's credit rating and margin linkage mechanism.

"2017 Yunnan Electric Power Market Sales Company Credit Evaluation Mechanism (Trial)" provides: when the credit rating is raised, reduce credit margin of electricity sales companies to participate in the electricity market transactions. When the credit rating of electricity sales enterprise is Grade A, the deposit stipulated in the normal payment shall be paid; when the credit rating is AA level, the credit margin payment will be reduced by $50 \%$; when the credit rating of sales enterprise is AAA level, it is not necessary to pay the credit margin.

When the credit rating is down, increase the credit margin of electricity sales companies to participate in the electricity market transactions. When the credit rating is Grade $\mathrm{B}$, the credit margin payment is raised by $30 \%$; when the credit rating of the electricity sales enterprise is Clevel, the credit 
margin payment is raised by 50\%; when the credit rating of the sales enterprise is D level, the credit margin payment is raised by $100 \%$. Credit rating and corresponding margin payment is shown in Table 1.

Table 1. Credit rating and corresponding margin payment

\begin{tabular}{cl}
\hline Grade & Margin \\
\hline AAA & does not need to pay margin \\
\hline AA & down 50\% \\
\hline A & executed according to the specified value \\
\hline B & up 30\% \\
\hline C & up 50\% \\
\hline D & up 100\%
\end{tabular}

Value-added service deprivation mechanism based on credit evaluation of electricity sales enterprises. According to Article 3 of Chapter 4 of "the Measures for the Approval and Withdrawal of Electricity Sales Company", the sales company shall provide value-added services including, but not limited to, contractual energy management, comprehensive energy conservation, rational use of energy consultation and operation and maintenance of electrical equipment, and charge the corresponding fees.

But in order to reduce the credit risk, protect the rights and interests of users, we can deprive the right of the company which below a certain credit rating to carry out value-added services, only allowed to engage in the most basic purchase and sale of electricity services. At the same time, its credit information should be timely released and inform the upstream and downstream enterprises to reduce their risk.

Priority contracting mechanism based on credit evaluation of electricity sales enterprises. Similar to the power generation enterprises, electricity sale companies involved in bilateral transactions shall submit the trading agreement to the trading institution for record and accept the security check. When the agreement can not pass the security check, give priority to the higher credit rating of the sale of the company transactions to protect its operating profit.

\section{Design of credit rating service system of power users}

Through provide differentiated services to different credit levels of power users, we can produce a considerable degree of power users honest and trustworthy incentives. Differentiated services can include power quality services, power supply recovery services, low-cost direct purchase of electricity services, electricity payment services.

Power quality service. Power quality is the basic guarantee of many contemporary industrial products. Meanwhile, in order to provide high-quality power grid address, power grid enterprises needs to make a greater investment on the equipment, personnel, work arrangements and so on. Therefore, it is possible to provide a more secure power quality service for high quality credit customers, including the installation of the equipment after the maintenance of a certain credit rating, the priority of the arrangement and so on.

Power supply recovery service. Although the power system in general can maintain a reliable power supply, but in the peak load season, or encountered major disasters, will still inevitably encounter local power outages. In this case, priority service can be provided to key customers of high quality credit, providing support for maintaining basic production in the context of extremely tight supply of electricity.

Low-cost direct purchase of electricity service. For the power users with better comprehensive credit, in the wet season we can encourage them to use more electricity in a low-cost way. In order to avoid the waste water will often produce a part of the additional power generation, this part of the electricity price is generally low, if this time is not the peak season, and the power user's production cycle flexibility, we can consider giving priority to its short-term low-cost power supply agreement so that it can make full use of this part of the low-cost electricity during the agreement period to speed up 
production progress and reduce production costs. In view of the fact that electricity costs typically account for a large proportion of electricity users' production costs, this incentive mechanism will also generate considerable attraction for power users.

Priority transactions service. With the gradual development and maturity of the market, power users direct purchase of electricity contract volume of the total annual electricity consumption ratio will gradually increase, becoming an important trading varieties in the market, so we can design the corresponding transaction mechanism to protect the higher credit market members' priority transactions.

The mechanism is designed to examine the credit situation of the previous year. In the next year when signs the direct purchase of electricity contracts, for the same offer, the same curve deviation of the power users, give the higher credit rating of electricity users priority; for the arrears of electricity, the curve deviation is larger which are new users, then cancel its participation in power users direct purchase market qualification.

Electricity payment service. There are a variety of electricity payment ways in China. For example, there is a pre-purchase electricity card, that is, "first pay, after use", and some according to the record of the energy meter to be settled. For power users, as their electricity charges are often huge, so directly related to the cash flow of power companies, if the arrears will cause adverse consequences, we need to give special attention. However, if the electricity bill can be paid relatively late in the period, it is a great attraction to the electricity user itself and can provide a time space for the cash flow. Therefore, for good credit users, we can consider charging electricity monthly, while for the poor credit level users, charge electricity weekly, and they need to purchase electricity in advance, thus forming a trustworthy incentive.

\section{Conclusions}

The credit rating service system of power market introduces credit factors into market rules, enabling higher credit market members to get better service and profit opportunities, to limit market transactions for poor credit market members. On the one hand, it makes the market members to actively improve their credit, reduce the act of dishonesty, on the other hand, it makes credit as one of the elements of market competition, maintaining the market fair.

\section{References}

[1] Lu Binggen. Discussion on Credit Construction in Electric Power Industry[J]. China Electric Power Enterprise Management, 2013, (16): 13-14.

[2] Wang Zhifei. Power customer credit rating classification and differentiated service strategy research[J]. Modern business, 2010, (14): $128+127$.

[3] Song Ting, Li Jiang. Research on Differentiated Service Marketing Strategy of Electricity Customer Credit Level[J]. Journal of Shanghai Dianli University, 2009, (01): 83-86. 